\title{
Contribution of extreme meteorological forcing to vertical mixing in a small, shallow subtropical lake
}

\author{
Nobuaki KIMURA, ${ }^{1}$ Wen-Cheng LIU,${ }^{2 *}$ Jeng-Wei TSAI, ${ }^{3}$ Chih-Yu CHiu, ${ }^{4}$ Timothy K. KRATZ, ${ }^{5}$ Akira TAI ${ }^{1}$ \\ ${ }^{1}$ Department of Civil Engineering, Kyushu University, 744 Motooka, Nishi-ku, Fukuoka 8910395, Japan; ${ }^{2}$ Department of Civil and \\ Disaster Prevention Engineering, National United University, Miao-Li 36003 Taiwan; ${ }^{3}$ Department of Biological Science and \\ Technology, China Medical University, Taichung 40402, Taiwan; ${ }^{4}$ Research Centre for Biodiversity, Academia Sinica, Taipei 115 , \\ Taiwan; ${ }^{5}$ Trout Lake Station, University of Wisconsin-Madison, Boulder Junction WI 53706, USA \\ *Corresponding author:wcliu@nuu.edu.tw
}

\begin{abstract}
Studying mixing processes in a stratified lake is important for understanding the biological, chemical and physical processes occurring there. Statistical analyses were performed of data from a small, shallow, stratified lake in a subtropical alpine region (YuanYang Lake in Taiwan) to determine the predominant physical factors in heavy-rainfall-induced mixing. This study focused on both vertical mixing in the entire water column and surface-layer mixing extending to the upper thermocline. The effects of meteorological driving forces, such as wind, heating/cooling and inflow on vertical mixing and surface layer mixing, were evaluated using the relationships between each driving force and the change in thermal stability between the pre-mixing and mixing periods. For surface layer mixing, a comparison between penetrative convection related to heating/cooling and wind-related friction velocity was conducted for each heavy rainfall event. A heat content parameter measuring thermal potential energy was introduced to further investigate inflow effects (e.g., effects of changes in discharge volume and temperature) on vertical mixing during heavy rainfall events. Results show that wind input affected vertical mixing more significantly than did other meteorological forcing factors during storm-dominant events. Indeed, wind energy input in the surface layer was more pronounced than was energy of heating/cooling for surface layer mixing. Furthermore, inflow effect was shown to be crucial during large scale and extreme weather events (i.e,. lower air pressure events) in the vertical mixing process. Forcing by heating/cooling likely contributes less to mixing because it is likely less dynamic than the wind and inflow inputs with respect to internal response of the lake. In addition, a principal component analysis (PCA) modified by partial correlation was performed to verify the results quantitatively. The first and second components, which accounted for more than $90 \%$ of the total variance in the PCA, showed that the intensity of vertical mixing was affected primarily by windinduced turbulence and inflow intrusion and was only weakly associated with the effect of net heat balance. Considering the interactions between chemical and physical processes, inflow intrusion may have an effect on dissolved oxygen concentration in the lake.
\end{abstract}

Key words: Mixing; heat content; Schmidt stability; PCA; subtropical, small lake.

Received: March 2016. Accepted: September 2016.

\section{INTRODUCTION}

Vertical mixing is an important physical process in a small, shallow, stratified lake during the summer and it affects aquatic bio-chemical processes both before and after mixing (Jones et al., 2008; Tsai et al., 2008, 2011). Vertical mixing is normally caused by wind-driven circulation (Kullenberg, 1976), cooling-related convection (Read et al., 2012), and inflow from heavy rainfall inputs (Laborde et al., 2010). In general, temperate lakes experience destratification because of cooling and the strong wind-induced mixing that occurs during winter in a seasonal cycle of mixing (Sundaram and Rehm, 1973). However, owing to severe rainstorms, stratified temperate lakes may also get mixed during summer (Porter et al., 2005). This study focused on mixing that is strongly affected by severe rainstorms in a small, thermally stratified, shallow lake. The mixing is similar to that shown in the simple sketch in
Fig. 1a, which represents a typical temporal vertical profile of water temperatures during rainstorm-induced mixing. This transient thermal structure consists of a homogenous surface layer mixed and maintained by wind-generated turbulence (hereafter referred to as surface mixed layer, SML), a thermocline depth maintained by the net heat balance at the surface, and a bottom mixed layer maintained by bottom-shear turbulence (Fischer et al., 1979). In this vertical mixing process, cooling and wind-induced turbulence are the dominant driving factors (MacIntyre and Melack, 1982; MacIntyre, 1993; MacIntyre et al., 2002). The definition of SML is sketched in Fig. $1 \mathrm{~b}$.

In general, a small and shallow lake has a small volume for stored water; therefore, heavy rainfall events can bring an amount of inflow much larger than the lake volume (Kimura et al., 2012b). This situation suggests that heavy rainfall-induced inflow may play an important role in lake mixing (Fig. 1c). We hypothesised that in addition to cool- 
ing and wind-induced turbulence (Fig. 1b), an inflow effect, caused by changes in the discharge volume and temperature, is also a major factor influencing vertical mixing, although it is generally minor (Fig. 1c). Using heat content as an effective indicator (Wetzel and Likens, 2000), might be helpful for assessing the effect of inflow. Moreover, comparing the contributions of these different physical factors to vertical mixing requires a quantitative analysis using the same physical variables, for example, energy and force. Some studies use the surface energy budget to compare the effects of forcing on lake mixing (MacIntyre et al., 2002). However, to the best of our knowledge, no factor analysis has been performed to determine the relative effect of physical factors on vertical mixing.

The purpose of this study was to determine which physical process among the major driving forces related to meteorological (MET) forcing (i.e., wind, heating/cooling, inflow) is the primary cause of mixing related to heavy rainfall events in a small, shallow, stratified lake. We focused on both vertical mixing throughout the entire water column and the SML. The former describes complete mixing from the lake surface to the bottom, caused mainly by wind, heating/cooling, and inflow. The latter describes mixing within the surface layer directly affected by wind forc- ing and heating/cooling (Imberger, 1985; Ishikawa and Tanaka, 1993), which typically extends from the lake surface to the upper thermocline (MacIntyre et al., 2002). For entire vertical mixing, we analysed the relationships between the forces using a mixing indicator of thermal stability and an indicator that can measure the effect of inflow on vertical mixing. In the SML, a comparison between the wind-induced friction velocity and the heating/cooling-related convection velocity was conducted. In these analyses, we assumed that implementing the seasonal trend frame work could be performed for short-term events like rainstorm-induced mixing. In addition, we performed a quantitative statistical analysis using principal component analysis (PCA) to determine which forces played significant roles in lake mixing and to describe a correlation between physical and chemical factors.

\section{METHODS}

\section{Instrumented buoy and field site}

Yuan-Yang Lake (YYL) is a shallow (4.5 m maximum depth and approximately $1.7 \mathrm{~m}$ mean depth) and small $\left(3.6 \times 10^{4} \mathrm{~m}^{2}\right)$ lake situated $1670 \mathrm{~m}$ above mean sea level (a)

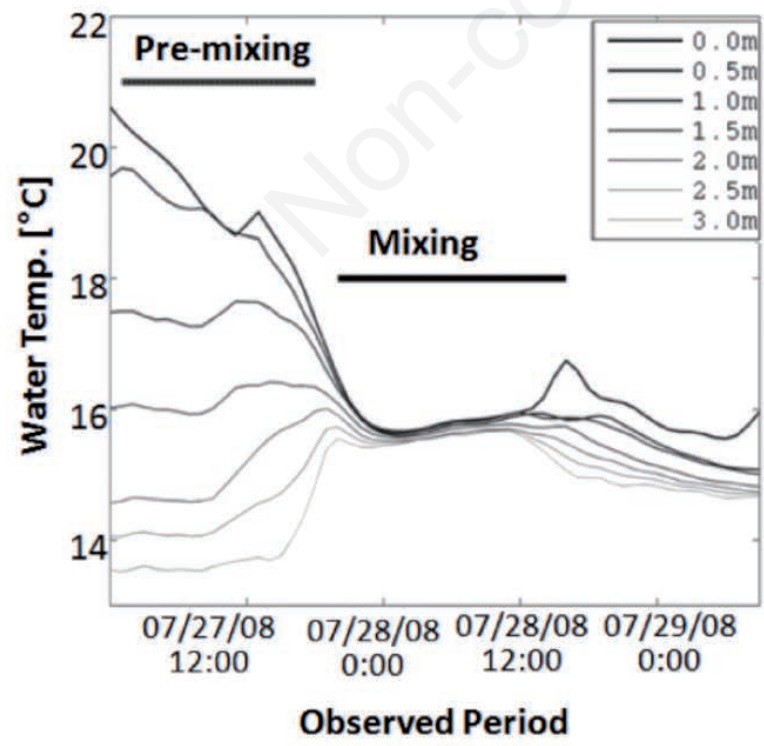

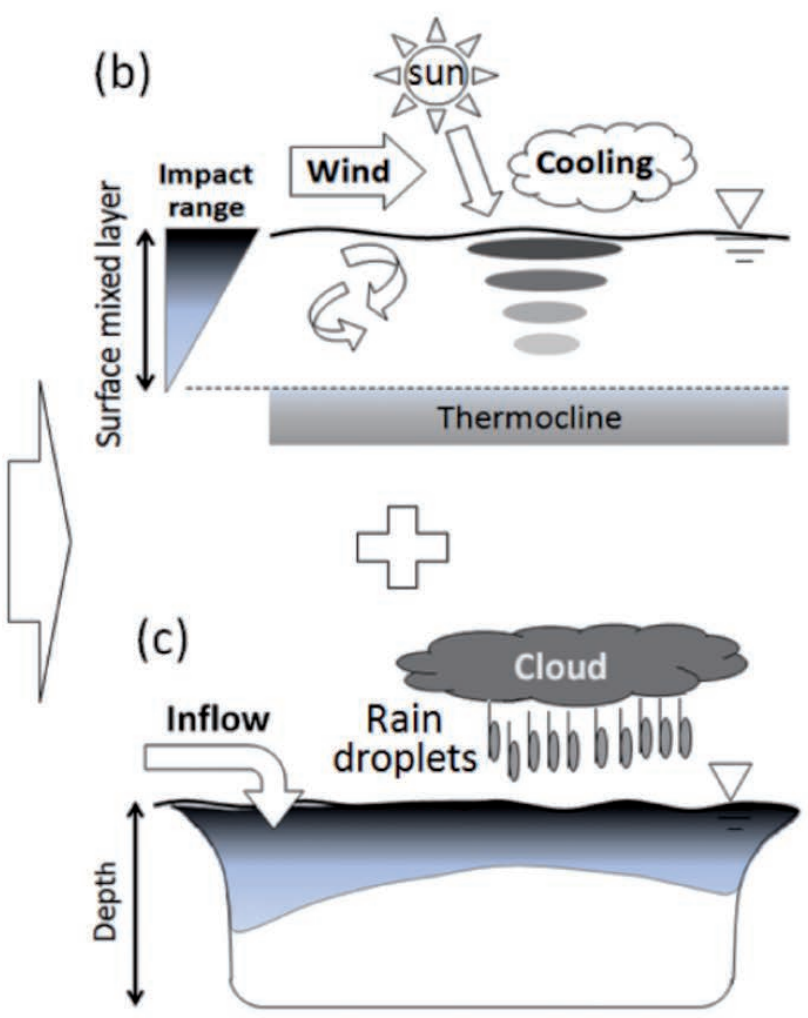

Fig. 1. Typical mixing pattern. a) Example caused by heavy rainfall event during water temperature profiles from surface to bottom layers in July 27-29, 2008. b) Sketch of surface layer mixing. c) Entire vertical mixing. 
in north-central Taiwan $\left(24^{\circ} 35^{\prime} \mathrm{N}, 121^{\circ} 24^{\prime} \mathrm{E}\right)$. The lake is partly surrounded by wetlands $\left(2.2 \times 10^{4} \mathrm{~m}^{2}\right)$ (Fig. 2). It has only one outlet, one dominant inlet and minor inlets from the northwest to the northeast. The steep catchment and part of the headwater area of the Tahan River $\left(3.7 \times 10^{6}\right.$ $\mathrm{m}^{2}$ ) are dominated by cypress forest. The lake is subjected to three to seven typhoons each year in summer and autumn, which generally accounts for more than $40 \%$ of the annual precipitation. Wind speed over the lake is relatively weak (normally $0-1.0 \mathrm{~m} \mathrm{~s}^{-1}$ ). The dominant wind directions are from the east and southwest due to the Vshaped valley oriented east-west (http://conservation.forest.gov.tw/). Seasonal thermal stratification starts developing from late spring on, is stable with a $>10^{\circ} \mathrm{C}$ gap during summer, and then weakens due to mixing processes. Additionally, several cycles of destratification and stratification occur every year owing to typhoons. During a severe rainstorm, significant runoff occurs that partly includes ground water (hereafter referred to as inflow in this study). The inflow contains less-turbid water because the lake is surrounded primarily by pristine dense forest and is partly connected to wetland.

Wireless auto-data collection systems (Porter et al., 2005) have been used since spring 2004 in YYL. Measurements from spring 2004 to autumn 2010 were obtained with an instrumented buoy placed in the western, deepest portion of the lake (Fig. 2). The YYL buoy was equipped with an anemometer (model 03001, R.M. Young, Traverse City, MI, USA) $2.0 \mathrm{~m}$ above the water surface and a thermistor chain (Templine, Apprise Technologies, Duluth, MN, USA) below the water surface with 10 sensors spaced at intervals of 0.25 to $0.5 \mathrm{~m}$, to a depth of $3.5 \mathrm{~m}$. Additionally, we placed a dissolved oxygen (DO) sonde (600-XLM, YSI Inc., Yellow Springs, OH, USA) at $0.25 \mathrm{~m}$, which was

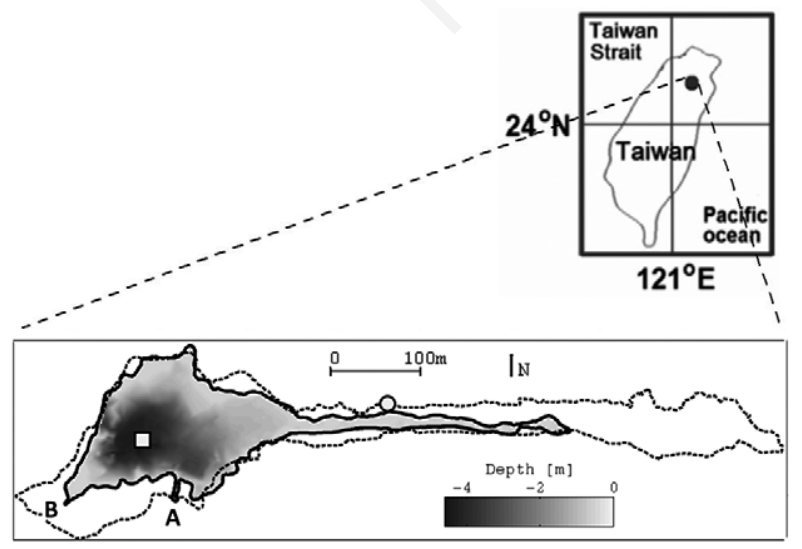

Fig. 2. YYL bathymetry map showing locations of the YYL buoy $(\square)$, water level observatory station $(\circ)$, dominant inflow (A), outflow (B), and wetland (dotted line). Bathymetry was measured with a GARMIN Sounder in the summer of 2007. fitted with an oxygen-temperature electrode (model 6562 , YSI). The water temperature profile between $3.0 \mathrm{~m}$ and the lake bottom (normally 4.1 to $4.5 \mathrm{~m}$ ) was assumed to be relatively constant as evidenced by point-based data that exhibited only $1.5^{\circ} \mathrm{C}$ difference between 3.2 and $4.1 \mathrm{~m}$ when the temperature at the surface was $23.1^{\circ} \mathrm{C}$ and $12.1^{\circ} \mathrm{C}$ at the bottom (July, 2009). The temperature difference between the surface and the bottom normally ranged from 9 to $13^{\circ} \mathrm{C}$ (during summer at the buoy) according to the oxygen-temperature electrode. An observatory station on the eastern lakeshore recorded water level (PS 9800(1), Instrumentation Northwest Inc., Kent, WA, USA). A landbased MET station approximately one km from YYL monitored air temperatures (HMP50-L, Vaisala, Vantaa, Finland), the relative humidity (same sensor as for the air temperature), air pressures $1.7 \mathrm{~m}$ above the ground level (090D, Met One Instruments, Inc., Grants Pass, OR, USA), shortwave radiation at $4.0 \mathrm{~m}$ above the ground level (Model PSP, Eppley Laboratory, Inc., Newport, RI, USA), and precipitation (rain gauge, Takeda Co., Osaka, Japan). These datasets were mostly unaffected by the ground or water surface where they were measured, except for humidity. Humidity in the surrounding environment was similar to that over the lake as it is typically high everywhere during typhoon events. At the buoy, water level and MET data were measured every $10 \mathrm{~min}$. The field data from the instrumented buoys are accessible from the Global Lake Ecological Observatory Network website at http://www. gleon.org. The dataset data used in this study is an extension of a previous study (Kimura et al., 2014).

\section{Field data analyses}

Because of heavy-rainfall events caused by typhoons during summer to early autumn, vertical mixing often occurs in the thermally stratified YYL in Taiwan. We define this mixing as heavy-rainfall-induced mixing. This vertical mixing may be caused primarily by three MET-forcing factors: wind, heating/cooling and inflow. The quantitative aspects of these factors can be measured as wind shear stress $(\tau)$, net heat balance $\left(H_{\text {net }}\right)$ and increase of the water level $\left(h_{G A P}\right)$, which is defined by the difference, or gap, between the minimum and maximum water levels during mixing. $h_{G A P}$ was employed as an inflow-related variable. The variables $\tau$ and $H_{n e t}$ were computed using theoretical and empirical equations, given by

$\tau=\rho_{a} u_{*}^{2}$,

$H_{n e t}=$ (shortwave radiation $)+$ (longwave radiation)

+ (latent heat $) \pm($ sensible heat $)$,

where $\rho_{a}$ is the air density $\left(\mathrm{kg} \mathrm{m}^{-3}\right)$ and $u_{*}$ is the surface friction.

To measure the strength of stratification and to com- 
pare the different factors, a quantitative indicator (Schmidt stability $S_{t}$ ) was introduced,

$$
S_{t}=\frac{g}{A_{0}} \int_{0}^{z_{m}}\left(z-z_{E}\right) A(z)[\bar{\rho}-\rho(z)] d z,
$$

where $\bar{\rho}$ is the mean density $\left(\mathrm{kg} \mathrm{m}^{-3}\right)$, is the height (m) at $\bar{\rho}$ from the bottom, $z$ is the height (m) from the lake bottom, $z_{m}$ is the maximum height (m), $\rho$ is the density $\left(\mathrm{kg} \mathrm{m}^{-3}\right), A_{0}$ is the area $\left(\mathrm{m}^{2}\right)$ at the surface and $A(z)$ is the area $\left(\mathrm{m}^{2}\right)$ at $z$. Note that $S_{t}$ is a more appropriate indicator of the stratification strength than the temperature difference between surface and bottom waters because it can quantify the shape of the vertical temperature profile (i.e. a sharp or linear gradient with respect to depth). In order to understand surface mixing, heating/cooling-related and wind forcing-related variables (i.e. penetrative convection velocity $w_{*}$ and water friction velocity $u_{*_{w}}$ ) were compared. These velocities are given by:

$w_{*}=\left(-\alpha g z_{t} H_{n e t} / \rho_{0} c_{p}\right)^{1 / 3}$,

$u_{*_{w}}=\left(\tau / \rho_{0}\right)^{1 / 2}$,

where $\rho_{0}$ is the water density $\left(\mathrm{kg} \mathrm{m}^{-3}\right), c_{p}$ is the specific heat capacity of water $\left(\mathrm{J} \mathrm{kg}^{-1}{ }^{\circ} \mathrm{C}^{-1}\right), g$ is the acceleration of gravity $\left(\mathrm{m} \mathrm{s}^{-2}\right)$ and $\alpha$ is the coefficient of thermal expansion $\left({ }^{\circ} \mathrm{C}^{-1}\right)$.

Taking into account the energy balance in the water column determined by the net surface heat flux, wind-induced turbulence and inflow temperature; is crucial for understanding the internal response to the forcing factors: wind, heating/cooling, and inflow. We introduced net heat content $\left(Q_{t}\right)\left(\mathrm{J} \mathrm{m}^{-2}\right)$ to compare the energy balance between the three factors, given by

$Q_{t}=\frac{c_{p} \rho_{0}}{A_{0}} \int_{0}^{z_{m}} T(z) A(z) d z$,

where $T$ is the temperature $\left({ }^{\circ} \mathrm{C}\right)$. The Birgean heat budget $\left(\mathrm{J} \mathrm{m}^{-2}\right)$ is a parameter showing the change of the heat content, given by

$$
B_{h}=\frac{q_{t \max }-q_{t \min }}{A_{\mathrm{med}}},
$$

where $q_{t \max }$ is the maximum of $A_{0} Q_{t}, q_{t \text { min }}$ is the minimum of $A_{0} Q_{t}$ and $A_{\text {med }}$ is the mean surface of the lake $\left(\mathrm{m}^{2}\right)$. More detailed information for the above equations is shown in Supplementary Material I.

\section{Modified principal component analysis}

In the entire water body, each factor can be partially categorised by their physical features, such as wind-induced turbulence and the heating/cooling process. We used the PCA, a linear transformation technique that ranks a set of variables, in order to produce components (data grouped by similar characteristics) in descending order from higher to lower score components (Hotelling, 1933). We followed the method described by Lin et al. (2005) (Supplementary Material II). We assumed that these components corresponded to some physical features in the lake. To indicate the relative strength of stratification, we introduced a ratio of the difference in $S_{t}$, defined as $\left[S_{t}\right.$ (pre) $-S_{t}$ (mixing) $] / S_{t}$ (pre) where 'pre' is a pre-mixing period, hereafter referred to as the $S_{t}$ ratio. This $S_{t}$ ratio is used as an indicator to show vertical mixing intensity. The pre-mixing period was defined as the one day before the mixing started because these days were assumed to be a non-typhoon event. Variables during the pre-mixing period were averaged over each day. Four variables $\left(S_{t}\right.$ ratio, $\tau, H_{\text {net }}$ and $h_{G A P}$ ) were used in our PCA procedures. The detailed procedure of the PCA is described in Supplementary Material II.

During data processing, missing values were not interpolated nor extrapolated from the available data. Consequently, the incomplete heavy-rainfall-induced vertical mixing observed data for analysis was excluded from Tab. 1.

\section{RESULTS}

\section{Field data}

Field data was collected at the YYL buoy from spring 2004 to autumn 2010 (except for 2007 due to insufficient complete datasets for analysis). Fig. 3a shows the seasonal variation of hourly averaged water temperatures and thermocline heights $\left(z_{t}=z_{m}-z_{E}\right)$ from the surface. The hourly averaged variations in MET variables (shortwave radiation, air temperature, wind, and precipitation) corresponding to the measurement period of water temperature are shown in Fig. 3 b,c. Mixing often occurred in YYL in summer and early autumn (June to October) when large amounts of precipitation and high wind speeds (caused mostly by typhoons) were observed. In the winter, mixing also occurred at times when there were colder air temperatures and reduced shortwave radiation. The temporal variation of the water column temperature indicates that typhoons caused complete or partial mixing (Fig. 3a, Tab. 1).

\section{Major physical process in vertical mixing}

Using thermal profiles and the lake bathymetry information, the strength of heavy-rainfall-induced vertical mixing in the water column can be represented by the $S_{t}$ ratio. Using $S_{t}$ ratios, Fig. 4 shows the relationships during heavy rainfall events between the strength of vertical mixing and three forcing factors: wind shear stress, net heat 
balance at the water surface and water level gap between peak and pre-mixing levels, which represents the effect from inflow/runoff inputs to the lake. Note that the water level gap was considered a forcing factor in this study although it is an indirect forcing factor through inflow/ runoff. These key factors were averaged over each mixing period induced by a heavy rainfall event. The duration of the mixing period was defined as the period from the beginning of mixing to the end of mixing (Fig. 1a).

We assumed that vertical mixing is stronger when the $S_{t}$ ratio is higher and that an extreme weather event occurs when the air pressure gap (the difference in air pressure between pre-mixing and mixing periods) is higher. In Fig. 4, the Pearson product-moment correlations $(R)$ between $S_{t}$ ratio and each MET forcing factor are 0.51 for $\tau$, 0.02 for $H_{\text {net }}$ and 0.71 for water level gap $(\mathrm{P}<0.05$ for all variables). The relationship between $\tau$ and the $S_{t}$ ratio shows that larger $\tau\left(>10^{-2} \mathrm{~N} \mathrm{~m}^{-2}\right)$ caused stronger vertical mixing $\left(S_{t}\right.$ ratio $\left.>0.4\right)$ (Fig. 4a). The relationship between $H_{n e t}$ and the $S_{t}$ ratio in Fig. 4b indicates that $H_{n e t}$ was not an important factor in the promotion of vertical mixing.
Large $S_{t}$ ratios ( $>0.5$ ) were strongly correlated with large water level gaps ( $>1.0 \mathrm{~m})($ Fig. $4 \mathrm{c})$. However, even for small water level gaps $(<1.0 \mathrm{~m})$, some large $S_{t}$ ratios were observed because weakly stratified waters caused by cool weather were already formed prior to the mixing event.

\section{Surface layer mixing}

In general, cooling and wind-driven turbulence cause deeper mixing; well below the surface layer. The inflow effect from discharge volume and temperature on surface mixing cannot be quantified, owing to the fact that inflowrelated discharge does not spread out spontaneously and homogenously over the lake surface. Nevertheless, we quantitatively examined only the contribution that the penetrative convection $\left(w_{*}\right)$ and the surface friction velocity $\left(u_{*_{w}}\right)$ in the lake surface layer reaching down to the upper thermocline make to vertical mixing throughout the entire water column. We assumed that three variables $\left(w_{*}, u_{*_{w}}\right.$ and thermocline depth) represent the degree of cooling, winddriven turbulence and deepening of mixing respectively. The quantitative comparison between $w_{*}$ and $u_{*_{w}}$ shows that

Tab. 1. Mixing information and observed/calculated dataset.

\begin{tabular}{|c|c|c|c|c|c|c|}
\hline Name of typhoon* & Period month/day/year & $\begin{array}{c}\text { Wind shear } \\
\text { stress } \\
\left(\mathrm{N} \mathrm{m}^{-2}\right)\end{array}$ & $\begin{array}{l}\text { Net heat } \\
\text { balance } \\
\left(\mathbf{W} \mathbf{m}^{-2}\right)\end{array}$ & $\begin{array}{l}\text { Water level } \\
\text { gap } \\
\text { (m) }\end{array}$ & $\begin{array}{c}\text { Stability } \\
\text { ratio }\end{array}$ & $\begin{array}{c}\text { Air pressure } \\
\text { gap } \\
\text { (hPa) }\end{array}$ \\
\hline Rananim & $08 / 11 / 2004-08 / 13 / 2004$ & 0.029 & -104 & 1.2 & 0.55 & 6.4 \\
\hline Aere & $08 / 23 / 2004-08 / 25 / 2004$ & 0.086 & -157 & 2.5 & 0.59 & 20.1 \\
\hline Haima-I ${ }^{\circ}$ & $09 / 09 / 2004-09 / 10 / 2004$ & 0.001 & -80 & 0.5 & 0.20 & 2.1 \\
\hline Haima-II $^{\circ}$ & $09 / 12 / 2004-09 / 13 / 2004$ & 0.010 & -99 & 0.8 & 0.08 & 6.4 \\
\hline Meari & $09 / 23 / 2004-09 / 25 / 2004$ & 0.002 & -98 & 0.3 & 0.37 & 3.1 \\
\hline HaiTang & $07 / 17 / 2005-07 / 19 / 2005$ & 0.052 & -146 & 2.6 & 0.59 & 25.7 \\
\hline Matsa & $08 / 04 / 2005-08 / 06 / 2005$ & 0.056 & -150 & 2.5 & 0.62 & 10.3 \\
\hline Sanvu & $08 / 12 / 2005-08 / 13 / 2005$ & 0.028 & -116 & 0.8 & 0.48 & 3.5 \\
\hline Talim & $08 / 31 / 2005-09 / 01 / 2005$ & 0.041 & -103 & 2.1 & 0.55 & 21.7 \\
\hline Bilis & $07 / 12 / 2006-0714 / 2006$ & 0.013 & -51 & 1.1 & 0.47 & 19.4 \\
\hline Kalmaegi & $07 / 17 / 2008-0719 / 2008$ & 0.001 & -44 & 0.5 & 0.57 & 14.6 \\
\hline Fungwong & $07 / 27 / 2008-07 / 29 / 2006$ & 0.029 & -49 & 2.0 & 0.67 & 31.2 \\
\hline Sinlaku & $09 / 11 / 2008-09 / 15 / 2008$ & 0.033 & -93 & 1.8 & 0.67 & 27.8 \\
\hline Hagupit & $09 / 22 / 2008-09 / 23 / 2008$ & 0.003 & -59 & 0.1 & 0.53 & 4.1 \\
\hline Jangmi & $09 / 26 / 2008-09 / 30 / 2008$ & 0.017 & -62 & 2.0 & 0.78 & 46.4 \\
\hline Linfa & $06 / 15 / 2009-06 / 16 / 2009$ & 0.002 & -77 & 0.3 & 0.23 & 3.0 \\
\hline Morakot & $08 / 06 / 2009-08 / 10 / 2009$ & 0.030 & -72 & 1.6 & 0.59 & 38.7 \\
\hline Parma & $10 / 02 / 2009-10 / 07 / 2009$ & 0.015 & -122 & 1.8 & 0.65 & 8.0 \\
\hline Namtheun & $08 / 29 / 2010-08 / 30 / 2010$ & 0.005 & -113 & 0.3 & 0.12 & 9.9 \\
\hline Meranti & $09 / 11 / 2010-09 / 12 / 2010$ & 0.003 & -119 & 0.4 & 0.18 & 4.0 \\
\hline Megi- $\left.{ }^{\circ}\right)$ & $10 / 16 / 2010-10 / 19 / 2010$ & 0.021 & -126 & 1.5 & 0.64 & 9.6 \\
\hline Megi-II $^{\circ}$ ) & $10 / 20 / 2010-10 / 23 / 2010$ & 0.009 & -87 & 1.0 & 0.33 & 8.6 \\
\hline
\end{tabular}

*Typhoon names were created by Taiwan Central Weather Bureau (www.cwb.gov.tw/eng/); ${ }^{\circ}$ twice mixing occurred when one typhoon was close to YYL. Note that observed values were averaged over the mixing period. 
for lower $u_{*_{w}}\left(<0.004 \mathrm{~m} \mathrm{~s}^{-1}\right), w_{*}$ is dominant. On the other hand, $u_{*_{w}}$ was slightly higher than $w *$ for some events with a higher air pressure gap (Fig. 5a). Fig. 5b shows that the ratio $u_{*_{w}} / w_{*}$ for some events was higher than the threshold $(0.75)$ indicating that for relatively large air pressure gaps, the turbulent energy from $u_{*_{w}}$ contributed more to the SML. In addition, a positive slope between $u_{*_{w}} / w_{*}$ and thermocline height from the water surface was strongly marked after the threshold. This implies that larger winds accompanying larger air pressure gaps promoted vertical mixing. However, the contribution from inflow to the SML is unclear because inflow potentially intrudes into the subsurface (e.g., thermocline) or lake bottom, depending on the water density of the inflow. Therefore, to evaluate the inflow effect on YYL vertical mixing throughout the entire water column, we had to introduce the heat content as a total heatstorage indicator. The heat content accounts for the variation in water levels, caused by inflow to the lake.

\section{Examples of typhoon-induced mixing events}

We assessed the inflow effect on heat content using two typhoon-induced mixing events with a similar wind shear stress: stronger vertical mixing during Typhoon Fungwong and weaker vertical mixing during Typhoon Rananim although we assumed that indirect effects of heat flux from the surface on heat content were weak (Fig. 4b). Fig. 6 shows MET forcing (wind, dry-air temperature and rainfall), water temperatures, water level and heat content with/without the inflow effect during the sampled events. The inflow effect was estimated indirectly from the change in lake volume by the increase in the water level. The effect of 'no inflow' was assumed to correspond to no change in the lake volume. Water temperatures were weakly stratified before Typhoon Rananim (Fig. 6a). Because of this, the difference between heat content with and without an inflow effect was

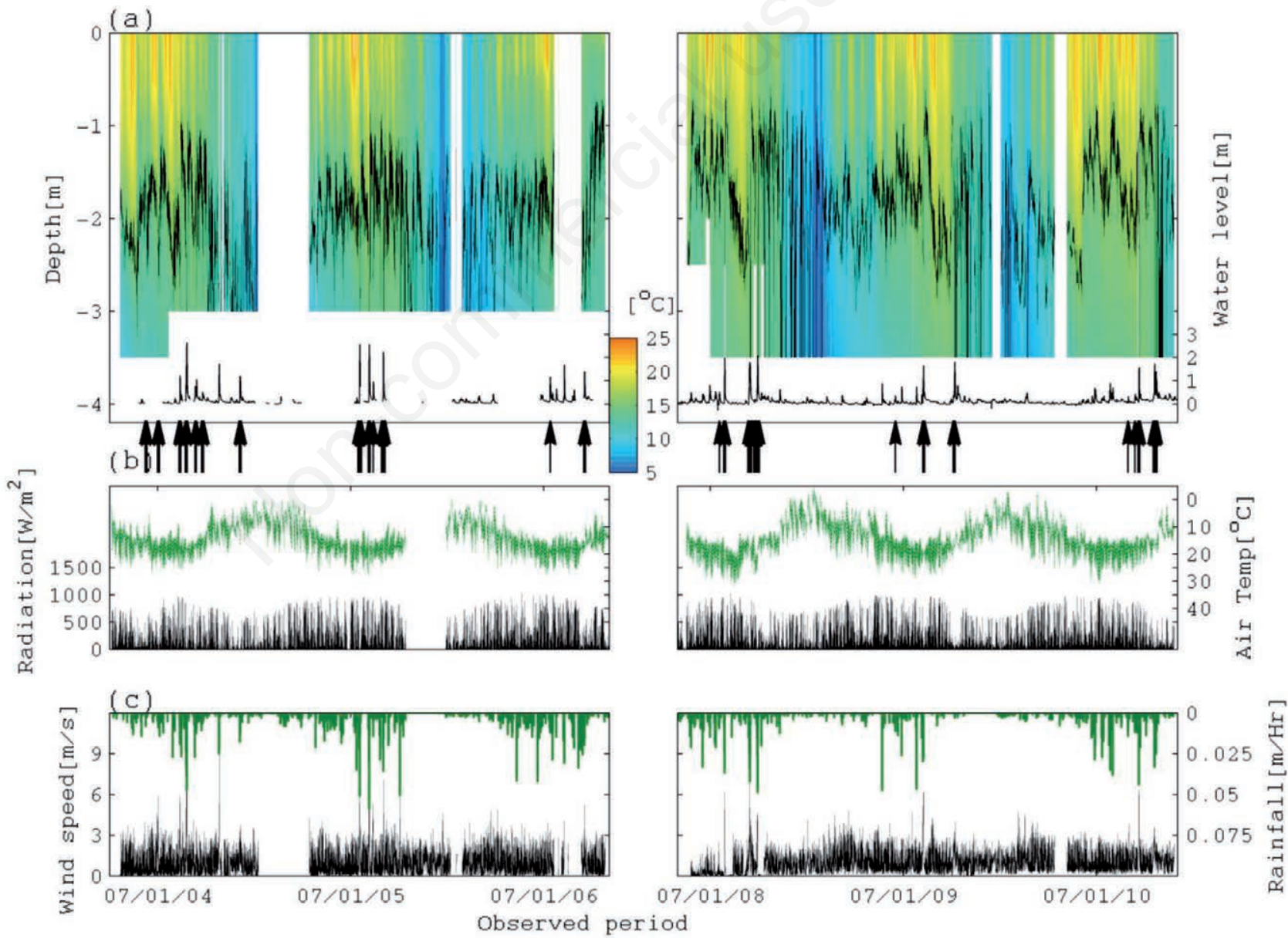

Fig. 3. Hourly averaged temporal variations in water temperature at the YYL buoy and MET conditions at the YYL buoy and the local MET station (1 km from YYL). a) Water temperatures (colour scale) from the surface to a depth of 3-3.5 m, water level, thermocline height $\left(z_{t}=z_{m}-z_{E}\right)$ from the surface (black line) and typhoon events (thin or thick arrows indicating weaker or stronger mixing). b) Incoming shortwave radiation (black line) and dry-air temperature (green line). c) Wind speed (black line) and precipitation (green bar) from spring 2004 to autumn 2010. The date notation indicates month/day/year. 
smaller $\left(\sim 67 \mathrm{MJ} \mathrm{m}^{-2} \mathrm{~h}^{-1}\right)$ (Fig. $\left.6 \mathrm{~b}, \mathrm{c}\right)$. In contrast, the strong vertical mixing and high inflow in the stratified YYL during Typhoon Fungwong resulted in a larger difference $\left(\sim 115 \mathrm{MJ} \mathrm{m}^{-2} \mathrm{~h}^{-1}\right)$ between inflow and no inflow heat content (Fig. 6 d,e,f). The changes of heat content suggest that the inflow effect becomes significant for vertical mixing accompanied by a large increase in water level and that the heat content is a good indicator for describing the strength of the inflow effect on vertical mixing.

\section{Heat content indicator of vertical mixing}

We used the Burgean heat budget $B_{h}$ (eq. 7) as an indicator to evaluate inflow effects, partial effects of cooling and indirect effects of wind-induced turbulence on vertical mixing. The inflow effect can be a dominant factor in heat content because of the large change in lake volume and the difference between the temperature of inflow and the lake surface. The increase in lake volume during mixing periods ranged from $\sim 10$ to $92 \%$ with a
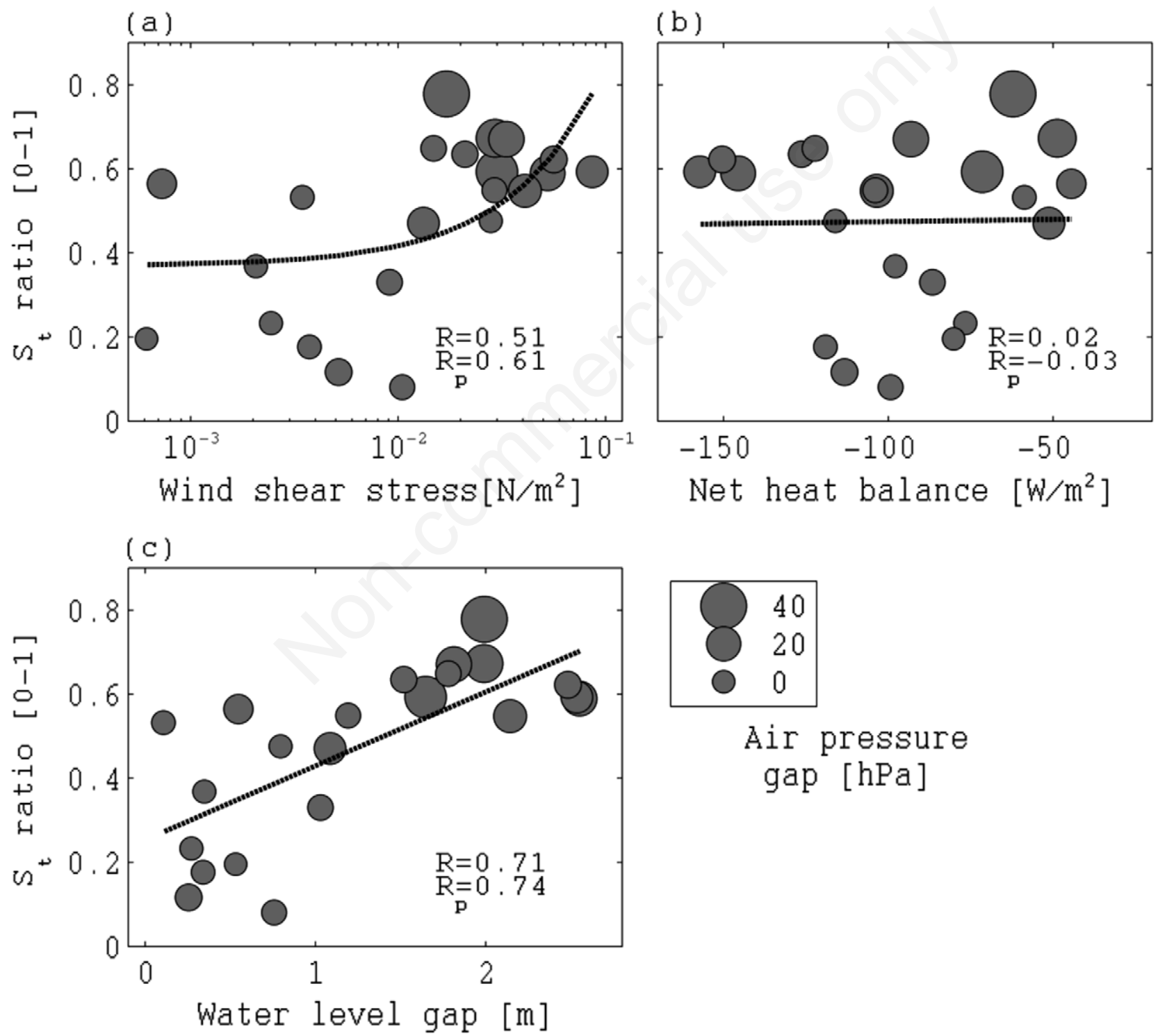

Fig. 4. Relationships $S_{t}$ of ratio between pre-mixing and mixing periods with three factors governing heavy-rainfall-induced mixing. a) Wind shear stress. b) Net heat balance. c) Water level gap all with linear regressions. The marker size represents the difference in air pressure between pre-mixing and mixing periods. $R$ and $R_{p}$ are the Pearson product-moment correlation and the Spearman's rank correlation coefficient, respectively. 
mean of $41 \%$ and a standard deviation of $23 \%$. The mean difference in temperature for all mixing events was $\sim 2.5^{\circ} \mathrm{C}$ with $1.3^{\circ} \mathrm{C}$ standard deviation, computed by an empirical regression between inflow and air temperatures if inflow temperature is uniformly spread from the inlet (Kimura et al., 2014). The mean and standard deviation value for inflow temperatures can be $\sim 10 \%$ and $\sim 5 \%$ of the entire lake temperature during typhoons. Note that, in reality, inflow could affect lake temperatures on a local scale. This trend typically has an annual cycle extending from the end of complete mixing to the beginning of the next complete mixing event and through the stratification period. We assumed that this annual cycle corresponds to a period of heavy-rainfallinduced mixing (Fig. 1a). $B_{h}$ with $\log _{10}$ scale for heavyrainfall-induced mixing events is moderately correlated with the $S_{t}$ ratio with an $R$ value of $0.60(\mathrm{P}<0.05)$ (Fig. $7 \mathrm{a})$. This implies that the effect of inflow on complete vertical mixing is moderate in the YYL.

However, it is necessary to verify the implementation of $B_{h}$ to heavy-rainfall-induced mixing. Seasonal trends of heat content have been investigated in numerous studies. For the YYL study, a short-term $B_{h}$ was computed for each vertical mixing. Fig. $7 \mathrm{~b}$ shows that the $B_{h}$ values for heavy-rainfall-induced mixings were less than half the magnitude (approximately 1 to $100 \mathrm{MJ} \mathrm{m}^{-2}$ ) of the empirical relationship between $B_{h}$ and $Z_{m}$ (Supplementary Ma- terial I). $B_{h}$ values are different from the empirical relationship because of the different dynamics between polymictic and meromictic lakes, and the difference in lake size and depth. Fig. 7b shows that the $B_{h}$ values gradually increased as maximum depth increased. The slope of the linear regression for higher air pressure gaps $(>5.2$ $\mathrm{m}$ for maximum depth) was similar to that $(\sim 0.45)$ of the empirical relationship.

\section{DISCUSSION}

Our goal in this section is to determine the major factor governing vertical mixing using a quantitative comparison of results in the previous section. The data analysis revealed three implications. In Fig. 4, the strength of the vertical mixing ( $S_{t}$ ratio) had a moderate relationship with wind shear stress $(\tau)$ and water level gap $\left(h_{G A P}\right)$, and a weak relationship with net heat balance $\left(H_{n e t}\right)$ based on the interpretation of the $R \mathrm{~s}$ (Evans, 1996). The moderate relationships of $\tau$ and $h_{\text {GAP }}$ were supported by other studies. For instance, wind forcing is a dominant factor for vertical mixing in a thermally stratified, shallow lake (Tuan et al., 2009). The relationship between wind speed and precipitation was positively strong for rainstorm events that caused vertical mixing in a small, shallow lake (Kimura et al., 2012a). (a)

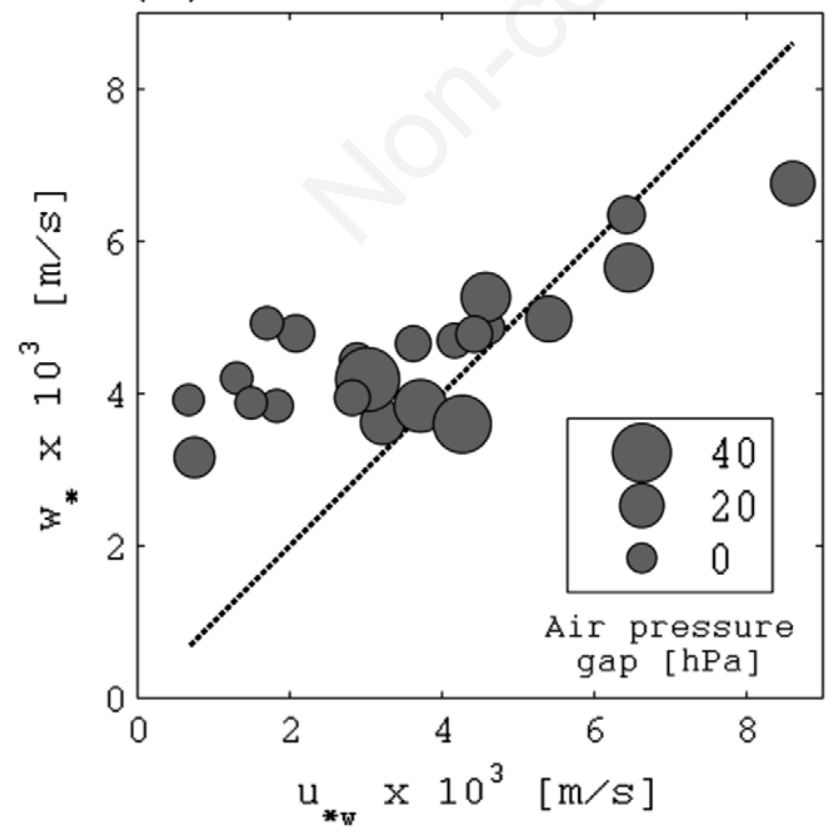

(b)

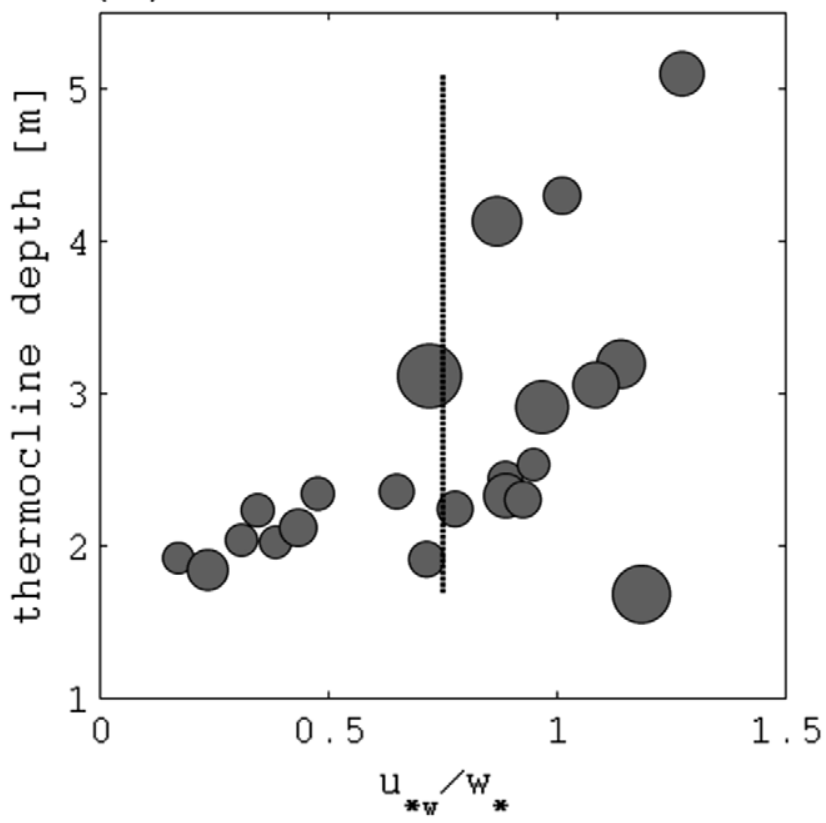

Fig. 5. Relationships between (a) $w_{*}$ and $u_{*_{w}}$ with the dotted line $w_{*}=u_{*_{w}}$, shown by the dotted line, and (b) $S_{t}$ ratio and the ratio $\left(u_{*_{w}} / w_{*}\right)$, where he dotted line indicates a ratio of 0.75 (threshold for balanced input from $w_{*}$ and $u_{*}$, Imberger, 1985). 
If focusing only on the SLM, mixing events accompanying large air pressure gaps were likely dominated by wind-turbulence mixing in the lake surface where the effects of wind and heating/cooling reached (Fig. 5). This implication supports the moderate relationship between $\tau$ and $S_{t}$ ratio (Fig. 4a) when the SML in each event was approximately equivalent to the depth from surface to bottom owing to surface layer mixing being deeper except for one event. In contrast, $w_{*}$ is dominant for low $u_{*_{w}}$ (Fig. 5a), which suggests that the SML extended to greater depths because of cooling (MacIntyre et al., 2002). The result from extreme weather events accompanying strong wind is different from those of other studies that show the change of dominant forcing, $H_{n e t}$ or $\tau$ for diurnal variation
(MacIntyre et al., 2002), and the dependency on lake surface size for seasonal variation (Read et al., 2012).

The impact of inflow on entire vertical mixing was also very significant, as revealed by the heat content indicator for two larger, extreme weather events (Fig. 6) as well as 20 other mixing events (Fig. 7). These inflow effects on vertical mixing are described over the lake under the assumption that horizontally homogenous temperatures exist in a small lake, to which typhoon-induced inflow/runoff waters move from any near-shore area. The large magnitude difference of heat content between off- and on-effects of inflows $\left(\sim 100 \mathrm{MJm}^{-2} \mathrm{~h}^{-1}\right.$ in Fig. 6f) likely corresponded to the seasonal difference of heat content in a small, shallow template water-body
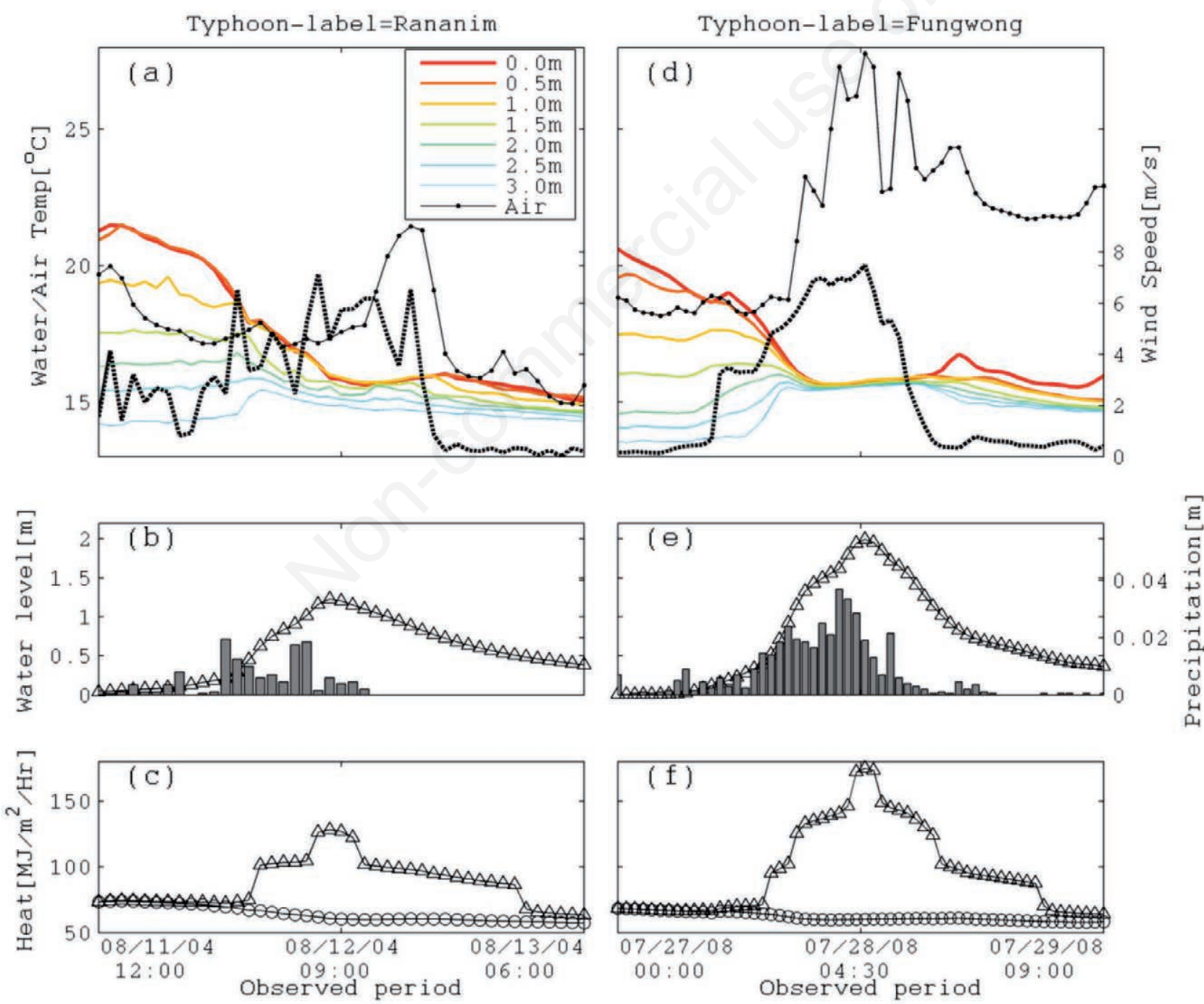

Fig. 6. Air temperature (dash-dot line), water temperature (coloured solid lines), wind speed (dotted line), precipitation (bar), water level (triangle) and heat contents with (triangles) and without (circles) the inflow effect with time during the weaker Typhoon Rananim $(a, b, c)$ and during the stronger Typhoon Fungwong $(d, e, f)$. The date and time notation indicates month/day/year, hour:minute. 
(Rodríguez-Rodríguez and Moreno-Ostos, 2006). The impact of typhoon-induced inflow was large although the inflow effect is usually minor in physical processes in large lakes (Michalsky and Lemmin, 1995). For understanding localized mixing for stratified water bodies, numerous spot measurements are necessary to reveal more precise characteristics of inflow-induced vertical mixing in specific areas with density plume phenomena (Laborde et al., 2010; Hogg et al., 2013). The overall suggestion is that the inflow had an important effect on vertical mixing although wind shear stress was also influential.

As a result, the above implications only describe a qualitative trend where statistical methods can determine which forcing factor is dominant in vertical mixing. For a more quantitative interpretation of these results focusing on common components among the observed data, we employed the PCA, modified by partial correlation in the pre-processing. The PCA was performed using the variables of Schmidt stability, wind shear stress, net heat balance, and water level gap (i.e., $S_{t}$ ratio, $\tau, H_{n e t}$ and $h_{G A P}$ ). The $S_{t}$ ratio was included as an index variable of the mixing in order to compare with the other variables. The matrix data of variance and covariance (Tab. 2) between two variables in each combination (e.g. $\tau$ and $H_{n e t}$ ) were used for the PCA computation. However, the P-values for the covariance between $H_{n e t}$ and $h_{G A P}$ or $S_{t}$ were high because of their weak relationships, which were likely caused by double counting of the wind effect even in $H_{\text {net }}$. Their relationships partly controlled by the third variable are likely spurious. To reduce these $\mathrm{P}$-values, eliminating the spurious relationships was performed using partial correlation. The improved matrix data are shown in Tab. 3.

The first and second principal components ( $\mathrm{PC} 1$ and PC2) are listed in Tab. 4. They accounted for $90 \%$ of the total variance and might explain the nature of the four variables. The eigenvectors (sets of weighted coefficients) for each principal component (PC) are also shown in Tab. 4. The large magnitudes of eigenvector elements in each PC potentially indicate that the element dominantly contributes to the PC (Liu et al., 2011). The values of loadings (i.e., eigenvector elements for $\tau, h_{G A P}$ and $S_{t}$ ratio) for the PC1 ( $\sim 54 \%$ of the variance) were relatively high,

Tab. 2. Variance and covariance among four variables.

\begin{tabular}{lcccc} 
& $\tau$ & $\boldsymbol{H}_{\text {net }}$ & $h_{\text {GAP }}$ & $S_{\text {t gap rate }}$ \\
$\tau$ & 1.00 & & & \\
\hline$H_{\text {net }}$ & -0.61 & 1.00 & & \\
\hline$h_{G A P}$ & 0.85 & $-0.41^{*}$ & 1.00 & \\
\hline$S_{t}$ ratio & 0.51 & $-0.18^{*}$ & 0.71 & 1.00 \\
\hline$n=22 ;{ }^{*} P>0.05$. & & & &
\end{tabular}

(a)

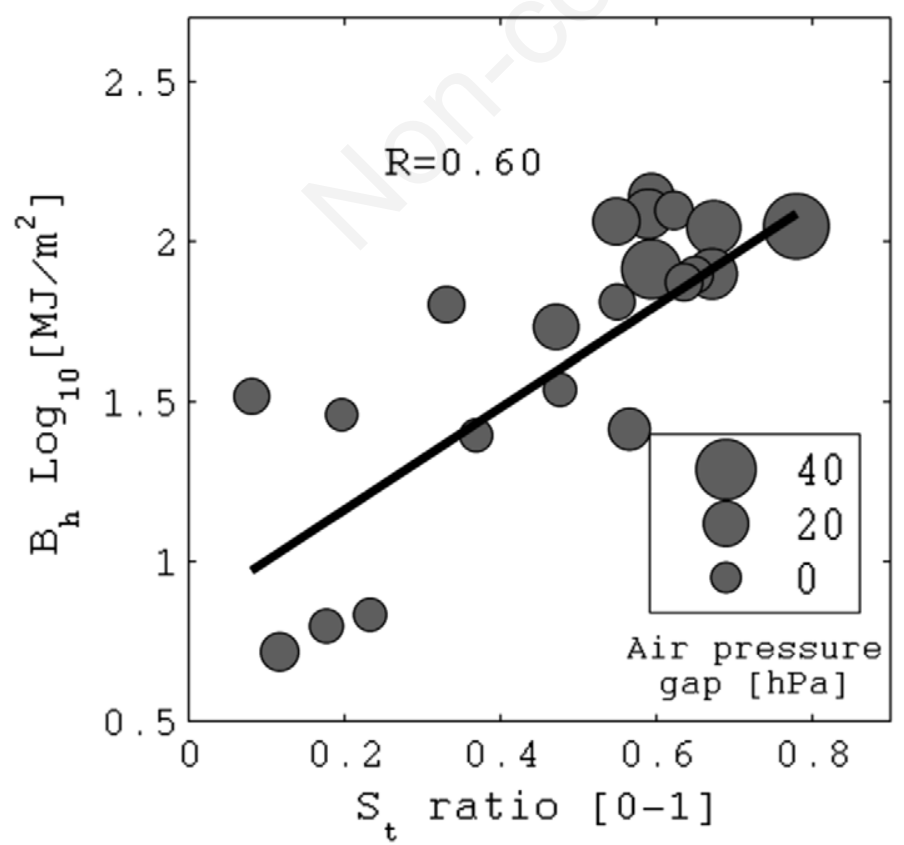

(b)

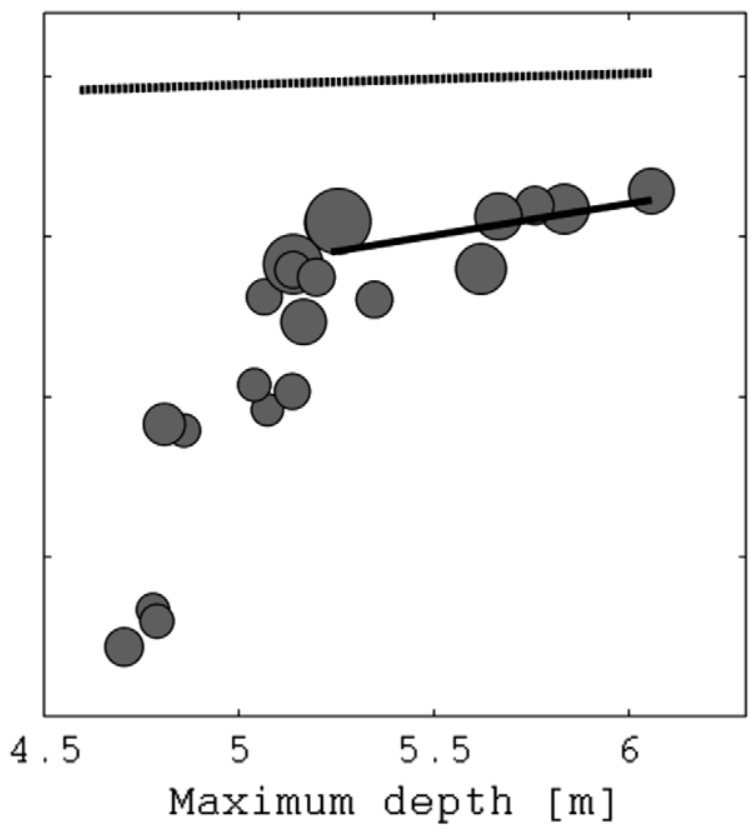

Fig. 7. Characteristics of the Birgean heat budge $\left(B_{h}\right)$ in $\log _{10}$ scale. a) Relationship between $S_{t}$ ratio and $B_{h}$. b) Relationship between maximum depth $\left(Z_{m}\right)$ and $B_{h}$ with the thick line showing the empirical relationship derived by Ambrosetti and Barbanti (2002). 
almost equivalent to each other, and their signs were the same. We assume that the $\mathrm{PC} 1$ represents the relatively strong effect of vertical mixing owing to the large value of $S_{t}$ ratio. Therefore, the implication is that the strength of the vertical mixing was significantly affected by both wind and inflow to the lake. They change in the same direction to increase or decrease the degree of stratification. In the quantitative comparison, the influence of inflow on mixing was slightly larger $(\sim 10 \%)$ than that of wind turbulence. Another assumption is that the PC2 represents a relatively weak effect of vertical mixing owing to the low value of the $S_{t}$ ratio. Thus, the factor related to cooling/heating $\left(H_{n e t}\right)$ was dominant, but it was weakly related to the intensity of mixing. Therefore, the intensity of the YYL mixing dynamics was caused primarily by wind turbulence and inflow intrusion, and the inflow effect was slightly stronger than that of wind shear stress.

Tab. 3. Variance and covariance partly modified by partial correlation.

\begin{tabular}{lcccc} 
& $\tau$ & $H_{\text {net }}$ & $h_{\text {GAP }}$ & $S_{\text {, ratio }}$ \\
$\tau$ & 1.00 & & & \\
\hline$H_{\text {net }}$ & -0.61 & 1.00 & & \\
\hline$h_{\text {GAP }}$ & 0.85 & $0.24 *$ & 1.00 & \\
\hline$S_{t}$ ratio & 0.51 & 0.49 & 0.71 & 1.00 \\
\hline$n=22 ; * P<0.3 ;$ others $P<0.05$. & & &
\end{tabular}
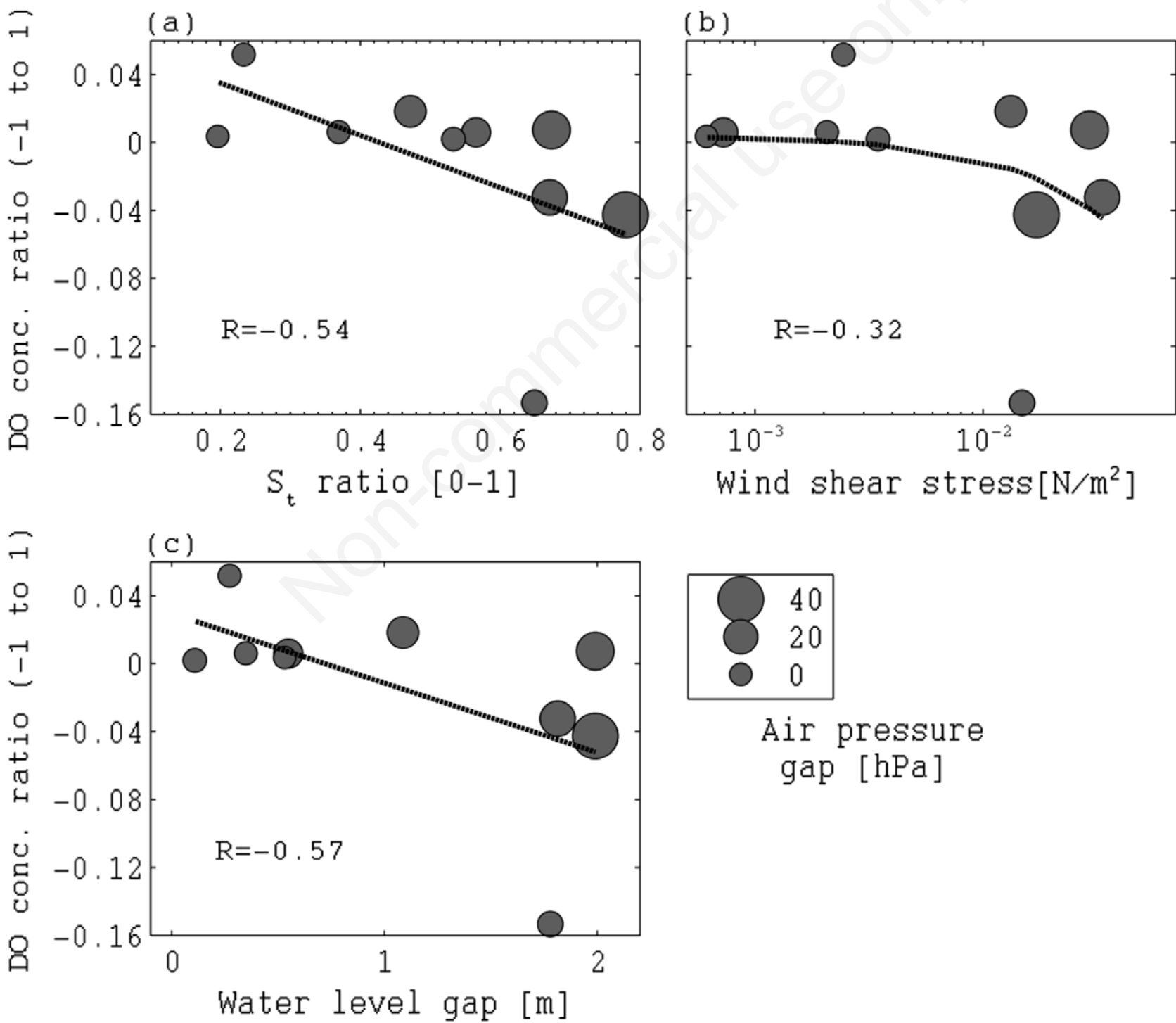

Fig. 8. Relationships of the DO conc. ratio at $0.25 \mathrm{~m}$ from the surface with $S_{t}$ ratio (a); wind shear stress (b), and water level gap (c), all with linear regressions. The marker size represents the difference in air pressure between pre-mixing and mixing periods. 
Tab. 4. Cumulative percentage of variances and loadings (eigenvectors) of four variables for significant principal components.

\begin{tabular}{lcc} 
& PC1 & PC2 \\
Cumulative percentage of variance $(\%)$ & 54 & 90 \\
Eigenvectors in each principal component & & \\
$\tau$ (wind shear stress) & -0.56 & 0.47 \\
$H_{\text {net }}$ (heating/cooling) & -0.05 & -0.81 \\
$h_{G A P}$ (inflow effect) & -0.63 & -0.06 \\
$S_{t}$ ratio (mixing intensity) & -0.56 & -0.32 \\
\hline
\end{tabular}

These conclusions are supported by our analytical results in the Results section.

As an extended discussion, to determine the effects of physical processes on water quality during vertical mixing, we examined the relationships between DO concentrations near the surface (i.e., the depth of $0.25 \mathrm{~m}$ ) and the dominant physical factors (i.e., wind and inflow). The difference in DO concentration between pre-mixing and mixing periods, normalised to the concentration during pre-mixing, was defined as $[\mathrm{DO}($ pre $)-(\mathrm{DO}$ (mixing) $]$ /DO(pre) (hereafter DO conc. ratio). However, because the number of DO concentration measurements available during typhoons was limited, the relationships are shown only for a few DO values (Fig. 8). The values of the DO conc. ratio were negative when DO concentration increased during strong mixing events. The DO conc. ratio shows a moderate negative correlation to the $S_{t}$ ratio (Fig. 8a). For mixing events, the weak, negative correlation between the DO conc. ratio and $S_{t}$ ratio could result from the balance among several mechanisms, such as the aeration of water by wind-induced turbulence (Melack, 1984), the cooling process in the surface water due to increasing oxygen solubility (Connell and Miller, 1984), the intrusion of inflow water with high DO concentration and the entrainment of anoxic hypolimnetic water to the surface layer (Tsai et al., 2008, 2011). The relation between the DO conc. ratio and the water level gap is more strongly correlated than that between the DO conc. ratio and wind shear stress (Fig. 8 b,c). These quantitative relationships imply that DO concentration in YYL was mixed more as a result of inflow, even though DO concentration is typically affected by wind-induced mixing and water temperature (Herb and Stefan, 2004). Thus, a small, shallow lake might be more strongly affected by inflow than by other MET factors. However, it is still necessary to understand how strong mixing increased the DO concentration, and this is planned for future work.

\section{CONCLUSIONS}

Using field data from an instrumented buoy in a small, shallow, stratified lake (YYL), we studied the character- istics of mixing induced by heavy rainfall events. We examined which MET forcing factor among three physical variables (wind, heating/cooling, and inflow) was dominant in the mixing process using: an indicator of thermal stability $\left(S_{t}\right.$ ratio) for mixing intensity, an indicator of heat storage $\left(B_{h}\right)$ for inflow over the entire lake volume, and the energy balance between friction velocity and penetrative convection at the lake surface. We revealed that:

- the strength of the vertical mixing is moderately related to wind shear stress;

- the effect of wind-induced turbulence on surface layer mixing is dominant during large wind-dominant rainfall events; and

- the effect of inflow on vertical mixing is significant for higher air pressure gaps as shown by the heat content indicator of large extreme-weather events.

In addition, further data analysis was performed quantitatively using PCA modified with partial correlation. The result showed that the $\mathrm{PC} 1$ consisted predominantly of wind and inflow inputs to the lake, with a relatively high value of vertical mixing intensity, and that the net heat balance was less correlated with the intensity of vertical mixing in the PC2. The relationships between DO concentration and physical factors also suggest that inflow may affect vertical mixing.

\section{ACKNOWLEDGMENTS}

This study was funded by the Taiwan National Science Council (NSC 97-2811-E-239-001), the Taiwan Academia Sinica (AS-98-TP-B06) and the Japan KAKENHI (Grant\# 24760398 and \# 26420499). We thank the field assistants (Y. H. Hsueh and P. Y. You), the IT technician (H. M. Chou) and also the US National Science Foundation for its supplement to the North Temperate Lakes, Long-term Ecological Research Project and the Gordon and Betty Moore Foundation for its support of the Global Lake Ecological Observatory Network, of which YYL is a part.

\section{REFERENCES}

Ambrosetti W, Barbanti L, 2002. Physical limnology of Italian lakes. 1. Relationship between morphometry and heat content. J. Limnol. 61:147-157.

Arya SP, 2001. Introduction to micrometeorology. Academic Press, New York: 420 pp.

Colomer J, Roget E, Casamitjana X, 1996. Daytime heat balance for estimating non-radiative fluxes of Lagoon Banyoles, Spain. Hydrol. Process. 10:721-726.

Connell DW, Miller GJ, 1984. Chemistry and ecotoxicology of pollution. J. Wiley \& Sons, New York: 444 pp.

Deardoff JW, 1970. Convective velocity and temperature scales for unstable planetary boundary layer and for Rayleigh convection. J. Atmos. Sci. 27:1211-1213.

Evans JD, 1996. Straightforward statistics for the behavioral sci- 
ences. Brooks/Cole Pub. Co., Pacific Grove: 624 pp.

Fischer HB, List EG, Koh RCY, Imberger J, Brooks NH, 1979. Mixing in inland and coastal waters. Academic Press, New York: $302 \mathrm{pp}$.

Guilford JP, Fruchter B, 1973. Fundamental statistics in psychology and education. McGraw-Hill, New York: 545 pp.

Henderson-Sellers B, 1986. Calculating the surface energy balance for lake and reservoir modeling: a review. Rev. Geophys. 24:625-649.

Herb WR, Stefan HG, 2004. Temperature stratification and mixing dynamics in a shallow lake with submersed macrophytes. Lake Reserv. Manage. 20:296-308.

Hicks BB, 1972. Some evaluations of drag and bulk transfer coefficients over water bodies of different sizes. Bound-Layer Meteorol. 3:201-213.

Hogg CAR, Marti CL, Huppert HE, Imberger J, 2013. Mixing of an interflow into the ambient water of Lake Iseo. Limnol. Oceanogr. 58:579-592.

Hotelling H, 1933. Analysis of a complex of statistical variables into principal components. J. Educ. Psychol. 24:417-441.

Hutchinson GE, 1957. A treatise on limnology.1. Geography, physics and chemistry. Wiley, New York: $1015 \mathrm{pp}$.

Idso SB, 1973. On the concept of lake stability. Limnol. Oceanogr. 18:681-683.

Imberger J, 1985. The diurnal mixed layer. Limnol. Oceanogr. 30:737-770.

Ishikawa T, Tanaka M, 1993. Diurnal stratification and its effects on wind-induced currents and water qualities in Lake, Kasumigaura, Japan. J. Hydraulic Res. 31:307-322.

Jones SE, Chiu CY, Kratz TK, Wu JT, Shade A, McMahon KD, 2008. Typhoons initiate predictable change in aquatic bacterial communities. Limnol. Oceanogr. 53:1319-1326.

Kimura N, Liu WC, Chiu CY, Kratz TK, 2012a. The influences of typhoon-induced mixing in a shallow lake. Lakes Reserv. Res. Manage. 17:171-183.

Kimura N, Liu WC, Chiu CY, Kratz TK, 2014. Assessing the effects of severe rainstorm-induced mixing on a subtropical, subalpine lake. Environ. Monit. Assess. 186:3091-3114.

Kimura N, Liu WC, Chiu CY, Kratz TK, Chen WB, 2012 b. Nearly real-time observation and prediction of physical processes in a typhoon-affected lake. Paddy Water Environ. 10:17-30.

Knauss JA, 1996. Introduction to physical oceanography. Prentice-Hall, Upper Saddle River: 320 pp.

Kondo J, 1975. Air-sea bulk transfer coefficients in diabatic conditions. Bound-Layer Meteorol. 9:91-112.

Kullenberg GEB, 1976. On vertical mixing and the energy transfer from the wind to the water. Tellus 28:159-165.

Laborde S, Antenucci JP, Copetti D, Imberger J, 2010. Inflow intrusions at multiple scales in a large temperate lake. Limnol. Oceanogr. 55:1301-1312.

Lin GF, Chen LH, Kao SC, 2005. Development of regional design hyetographs. Hydrol. Process 19:937-946.

Liu WC, Yu HL, Chung CE, 2011, Assessment of water quality in a subtropical alpine lake using multivariate statistical techniques and geostatistical mapping: a case study. Int. J. Environ. Res. Public Health 8:1126-1140.
MacIntyre S, Melack JM, 1982. Meromixis in an equatorial African soda lake. Limnol. Oceanogr. 27:595-609.

MacIntyre S, 1993. Vertical mixing in a shallow, eutrophic lake: possible consequences for the light climate of phytoplankton. Limnol. Oceanogr. 38:798-817.

MacIntyre S, Romero JR, Kling GW, 2002. Spatial-temporal variability in surface layer deepening and lateral advection in an embayment of Lake Victoria, East Africa. Limnol. Oceanogr. 47:656-671.

Melack JM, 1984. Amazon floodplain lakes: shape, fetch, and stratification. Verh. Internat. Verein. Limnol. 22:1278-1282.

Michalsky J, Lemmin U, 1995. Dynamics of vertical mixing in the hypolimnion of a deep lake: Lake Geneva. Limnol. Oceanogr. 40:809-816.

Patterson JC, Hamblin PF, Imberger J, 1984. Classification and dynamic simulation of the vertical density structure of lakes. Limnol. Oceanogr. 29:845-861.

Pond S, Phelps GT, Paquin JE, McBean G, Stewart RW, 1971. Measurements of the turbulent fluxes of momentum, moisture and sensible heat over the ocean. J. Atmos. Sci. 28:901-917.

Porter J, Arzberger P, Braun H, Bryant P, Gage S, Hansen T, Hanson P, Lin CC, Lin FP, Kratz K, Michener W, Shapiro S, Williams T, 2005. Wireless sensor networks for ecology. Bioscience 55:561-572.

Read JS, Hamilton DP, Desai AR, Rose KC, MacIntyre S, Lenters JD, Smyth RL, Hanson PC, Cole JJ, Staehr PA, Rusak JA, Pierson DC, Brookes JD, Laas A, Wu CH, 2012. Lake-size dependency of wind shear and convection as controls on gas exchange. Geophys. Res. Lett. 39:L09405.

Rodríguez-Rodríguez M, Moreno-Ostos E, 2006. Heat budget, energy storage and hydrological regime in a coastal lagoon. Limnologica 36:217-227.

Serreze MC, Barry RG, 2005. The arctic climate system. Cambridge University Press, New York: 413 pp.

Sundaram TR, Rehm RG, 1973. The seasonal thermal structure of deep temperate lakes. Tellus 25:157-168.

Tsai JW, Kratz TK, Hanson PC, Kimura N, Liu WC, Lin FP, Chou $\mathrm{HM}, \mathrm{Wu}$ JT, Chiu CY, 2011. Metabolic changes and the resistance and resilience of a subtropical heterotrophic lake to typhoon disturbance. Can. J. Fish. Aquat. Sci. 68: 768-780.

Tsai JW, Kratz TK, Hanson PC, Wu JT, Chang WYB, Arzberger PW, Lin BS, Lin FP, Chou HM, Chiu CY, 2008. Seasonal dynamics, typhoons and the regulation of lake metabolism in a subtropical humic lake. Freshwater Biol. 53:1920-1941.

Tuan NV, Hamagami K, Mori K, Hirai Y, 2009. Mixing by windinduced flow and thermal convection in a small, shallow and stratified lake. Paddy Water Environ. 7:83-93.

UNESCO, 1981. Tenth report of the joint panel on oceanographic tables and standards. UNESCO Technical Paper in Marine Science.

Wetzel RG, Likens GE, 2000. Limnological analysis. Springer, New York.

Yu SL, Hamrick JM, Lee DS, 1983. Wind effects on air water oxygen transfer in a lake. In: Proc. Symp. Gas Transfer at Water Surfaces, Cornell University, New York, USA, 13-15 June, 1983. 